Original Research Paper

\title{
The Effects of Subacute Ruminal Acidosis on Milk Fatty Acid Profile in Dairy Cattle
}

\author{
Mitchell, C., O. ALZahal, M.M. Or-Rashid, M.A. Steele and B.W. McBride \\ Department of Animal Biosciences, University of Guelph, Ontario, Canada N1G 2W1, Canada
}

\author{
Article history \\ Received: 20-12-2015 \\ Revised: 05-03-2016 \\ Accepted: 21-04-2016 \\ Corresponding Author: \\ O. ALZahal \\ Department of Animal \\ Biosciences, University of \\ Guelph, Ontario, Canada N1G \\ 2W1, Canada \\ Email: oalzahal@uoguelph.ca
}

\begin{abstract}
The objective of this experiment was to examine the effect of Subacute Ruminal Acidosis (SARA) on milk fatty acid (FA) profiles with emphasis on odd-chain and branched-chain FA. Sixteen multiparous Holstein dairy cows ( $618 \pm 35 \mathrm{~kg}$ of body weight, $221 \pm 32$ days in milk) were used in a randomized complete-block design. During week 1, all cows received a high-forage diet $(90 \%$ chopped grass hay, $5 \%$ grain mix, 5\% protein supplement, dry-basis; HF). During weeks 2 through 4, cows either continued receiving the HF diet or received a low-fiber diet (38\% chopped grass hay, 57\% grain mix, 5\% protein supplement, dry-basis; LF). Milk yield and dry matter intake were recorded daily, milk samples were collected twice weekly and ruminal $\mathrm{pH}$ was continuously recorded during the last $48 \mathrm{~h}$ of each week. Statistical analysis was conducted on weekly measuring Proc Mixed of SAS accounting for repeated measurement. The model included the fixed effects of diet, week, their interaction and block. Helmert contrasts were used to describe the difference between treatments over time. The dietary treatment induced a significant difference over time between treatments (diet by week 1 Vs. average week 2, 3 and 4; $<<0.05$ ). The treatment reduced $(\mathrm{p}<0.05)$ milk fat concentration $\left(\mathrm{g} 100 \mathrm{~g}^{-1}\right)$ of branched-chain FA (including 14:0 iso, 15:0 iso, 15:0 anteiso, 16:0 iso and 17:0 iso), 18:0, trans-11 18:1,cis-9, trans-11 conjugated linoleic acid (CLA), 18:3 n-3, 20:0, cis-11 20:1, 20:4 n-3,22:0 and 24:0. The treatment increased $(\mathrm{p}<0.05)$ milk fat concentration $\left(\mathrm{g} 100 \mathrm{~g}^{-1}\right)$ of odd-chain FA (including 11:0 and 13:0), 12:0, 13:0 antiso, cis-9 14:1, cis-12 18:1, cis-13 18:1, trans-6-8 18:1, trans-10 18:1 and trans-12 18:1. The treatment also increased $(\mathrm{p}<0.05)$ the concentration of cis-9, cis-12 18:2; trans-9, cis-11 CLA; trans-10, cis-12 CLA; and 20:4n-6. The results indicate that SARA is associated with a shift in odd-chain and branched-chain FA, which can be utilized to diagnose a cow with SARA.
\end{abstract}

Keywords: Subacute Ruminal Acidosis, Milk Fatty Acid, Odd-Chain, Branched-Chain

\section{Introduction}

Subacute Ruminal Acidosis (SARA) is a common ruminal digestive disorder in dairy cattle, which is caused by feeding rapidly fermentable carbohydrates (Plaizier et al., 2009). Typically, SARA is characterized by a $\mathrm{pH}$ depression below 5.6 for approximately 3-5 $\mathrm{h} \mathrm{day}^{-1}$ (AlZahal et al., 2007). The disease is capable of affecting feed intake; rumen microflora and digestion; milk production and can cause inflammation (Plaizier et al., 2009). Lactating dairy cattle rely on a diet rich in rapidly fermentable carbohydrates in order to meet their high dietary energy needs and to increase production efficiency (Steele et al., 2012).

In the United States studies have reported that approximately $19 \%$ of early lactation cows and $26 \%$ of mid lactation dairy cows have had SARA (Garrett et al., 1997). It has been estimated that the economic cost of SARA is around $\$ 1.12$ per cow per day (Stone, 1999), which could add up to 1 billion dollars annually (Donovan, 1997). The economic 
losses associated with SARA, include reduced milk production, decreased milk efficiency and increase death loss (Enemark, 2009). Thus early diagnosis and treatment of SARA could prevent economic losses (Enemark, 2009).

SARA does not often exhibit clear and overt clinical symptoms (Plaizier et al., 2009). The most common clinical signs of SARA are reduced or erratic feed intake; which are not unique to SARA and symptoms vary in each case, therefore SARA is difficult to detect (Plaizier et al., 2009). Currently, rumen $\mathrm{pH}$ parameters are used to diagnose SARA using stomach tubing or rumenocentesis, however these methods are expensive and invasive (Plaizier et al., 2009).

A new method to diagnose SARA has surfaced, in which milk Fatty Acids (FA) profiles are monitored in pooled milk samples (Fievez et al., 2012). Milk fat contains about 2 to $3 \%$ Odd- and Branched-Chain Fatty Acids (OBCFA) rising from microbial FA (Patel et al., 2013). OBCFA profiles in milk can be potential markers for duodenal flow of microbes The FA composition in cow milk can be altered through feeding (Patel et al., 2013), for example changing the forage proportion are known to alter FA profiles in milk (Chilliard et al., 2007); therefore OBCFAs could be used as a noninvasive tool to predict ruminal acidosis.

In a experiment conducted by Colman et al. (2010), diagnosis of acidosis was based on $\mathrm{pH}$ measurements; and OBCFA profiles within the milk (Colman et al., 2010). This experiment demonstrated the potential of using milk FA profiles in diagnosing acidosis, however a general classification model is still required (Fievez et al., 2012). Two other studies attempted to develop a discriminate function based on milk FA profiles (Van Nespen et al., 2015; Colman et al., 2010). Both studies identified C18:1 trans-10 and CLA cis-9 trans-11 as main discriminating factors; whereas the other FA may vary based on the microbiome (Van Nespen et al., 2005; Colman et al., 2010). Although the use of milk FA profiles is still limited to experimental treatments, it still shows some potential as a method to diagnose SARA (Fievez et al., 2012). The objective of this study was to investigate the effect of SARA on milk FA profile, with an emphasis on branched- and odd-chain FA.

\section{Materials and Methods}

The experimental procedures were detailed previously in Steele et al. (2012). Briefly, sixteen multiparous Holstein dairy cows $(618 \pm 35 \mathrm{~kg}$ of BW, $221 \pm 32$ DIM) were used in a randomized completeblock design. The cows were grouped by stage of lactation into 2 blocks ( $\mathrm{n}=8 \mathrm{each})$ and the cows within each block were randomly assigned into 1 of 2 dietary treatments. During week 0 (baseline), all cows received high-forage diets $(90 \%$ chopped grass hay, $5 \%$ grain mix, 5\% protein supplement, dry basis; HF). The chemical composition (\%) of the HF diet contained 88.2 DM, 16.2 CP, 31.8 ADF, 46.9 NDF, 2.2 EE, 10.6 Ash and 27.9 NFC and 7.4 starch (Steele et al., 2012). During weeks 1 through 3 , cows either continued receiving the HF diet or received a low-fibre diet $38 \%$ chopped grass hay, $57 \%$ grain $\operatorname{mix}, 5 \%$ protein supplement, \% DM; LF; Steele et al. (2012)). The chemical composition (\%) of the LF diet contained 88.2 DM, 14.5 CP, 17.6 ADF, 32.3 NDF, 2.5 EE, 7.1 Ash, 46.0 NFC and 32.1 starch (Steele et al., 2012)

Milk yield and DMI were recorded daily; milk samples were collected twice weekly and ruminal $\mathrm{pH}$ was continuously recorded during the last $48 \mathrm{~h}$ of each week (AlZahal et al., 2007). Milk samples were collected from each milking for the last $2 \mathrm{~d}$ of every experiment week and analyzed for milk composition at the CanWest DHI Milk Laboratory (Guelph, Ontario, Canada) using infrared spectroscopy (Milkoscan 400; Foss Electric, Hillerød, Denmark). Milk samples for FA analysis were collected during week 0 and week 3; and frozen immediately at $-20^{\circ} \mathrm{C}$ until analysis. Lipids for FA analysis in this study, were extracted as explained by Or-Rashid et al. (2009).

Statistical analysis of FA profile was conducted using Proc Mixed of SAS. The model included the fixed effects of the week (week 0 and 3), block and their interaction $(\mathrm{p}<0.05)$.

\section{Results and Discussion}

The goal of this study was to examine the effects that SARA had on milk FA profiles with an emphasis on OBCFA. To achieve this goal, cows were fed a LF diet, which contained $57 \%$ gain mix and $38 \%$ chopped grass hay. Cows receiving LF were on average $9 \mathrm{~h} / \mathrm{d}$ below $\mathrm{pH}$ 5.6 indicating severe SARA (Steele et al., 2012). LF diet compared with the HF diet had lowered DMI $(\mathrm{p}<0.01)$ by $1.7 \pm 0.31 \mathrm{~kg} / \mathrm{d}$; and decreased milk fat percentage $(\mathrm{p}<0.01)$ (Steele et al., 2012). The increase in energy density of the diet led to higher milk yield $(17.4 \pm 0.5 \mathrm{Vs}$. $23.4 \pm 0.9 \mathrm{~kg} / \mathrm{d})$; and higher protein yields $(559 \pm 16 \mathrm{Vs}$. $782 \pm 23 \mathrm{~g} / \mathrm{d}$ ) (Steele et al., 2012).

In agreement with ruminal $\mathrm{pH}$, total Short Chain FA (SCFA) concentreations were greater $(\mathrm{p}<0.01)$ in $\mathrm{HF}$ compared to LF (Steele et al., 2012). The concentrations of all SCFA were greater in HC cattle throughout the experiment, except for acetate and iso butyrate (Steele et al., 2012). Ruminal butyrate displayed the largest proportional increase $(\mathrm{p}<0.01)$ due to treatment $(6.1 \pm 1.6 \mathrm{mM})$ (Steele et al., 2012).

The treatment reduced $(\mathrm{p}<0.05)$ milk fat concentration $(\mathrm{g} / 100 \mathrm{~g})$ of branched chain FA (including 
14:0 iso, 15:0 iso, 16:0 iso and17:0 iso; Fig. 1), 15:0 anteiso, 18:0, 18:3 n-3, 20:0 cis-11, 20:4 n-3, 22:0 and 24:0. The reduced branched chain FAs is likely due to a decline in the forage: Concentrate ratio. Higher concentrations of branched chain FA in milk are typically a result of high forage diets, due to a larger population of cellulolytic bacteria that can produce acetate (Patel et al., 2013). Acetate can be elongated into branched-chain FAs, which will eventually be deposited into the milk (Patel et al., 2013). In SARA, there are more amylolytic bacteria in the rumen, which produce propionate, leading to less branched-chain FAs being produced (Fievez et al., 2012). Therefore, the

\section{iso $\mathrm{C} 14: 0$}

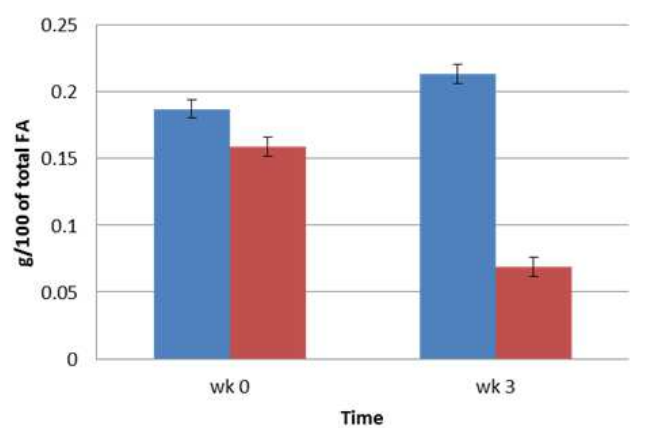

iso $\mathrm{C} 15: 0$
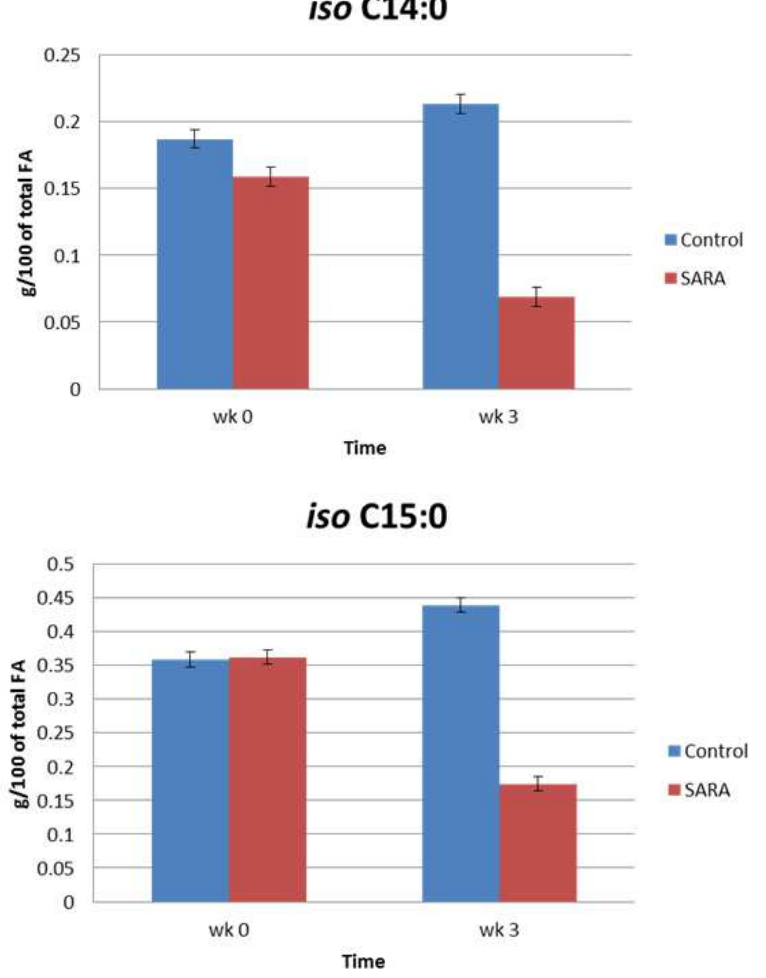

decreased branched-chain FAs in the milk, is likely a result of an acidic rumen changing the microbiome. Shingfield et al. (2005) conducted a study comparing two levels of concentrate with oil supplement on a diet based on grass silage. The study discovered that there was a higher concentration of iso $\mathrm{C} 17: 0$ and iso C:14 with a higher amount of forage in the diet (Shingfield et al., 2005). Vlaeminck et al. (2006) found similar results where iso C15:0 increased in proportion to grass silage. Another study by Patel et al. (2013) also discovered that augmented proportions of grass silage in the diet increased the branched-chain FAs iso $\mathrm{C} 15: 0$ and iso $\mathrm{C} 17: 0$.
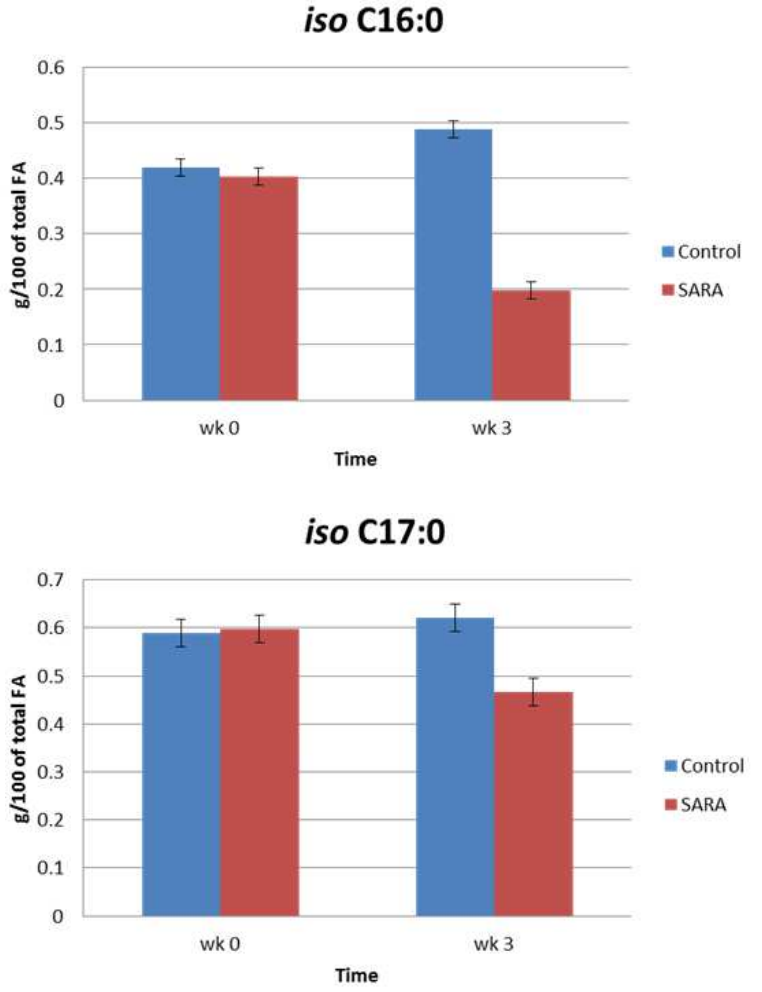

Fig. 1. The treatment reduced $(\mathrm{p}<0.05)$ milk concentration of branched chain FA iso $\mathrm{C} 15: 0$, iso $\mathrm{C} 16: 0$, iso $\mathrm{C} 14: 0$ and iso $\mathrm{C} 17: 0$ as seen in figure a-d

\section{C11:0}

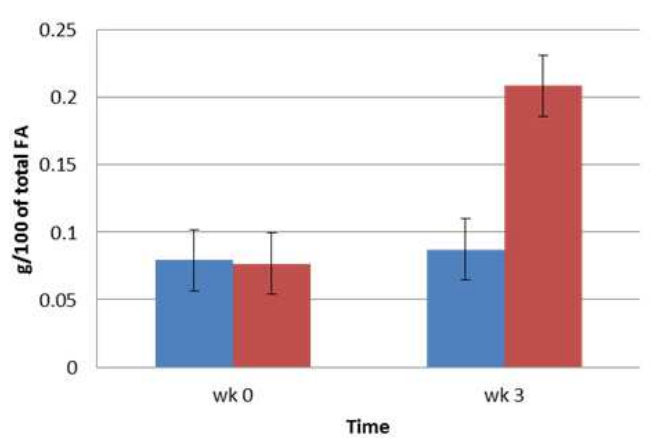

C13:0

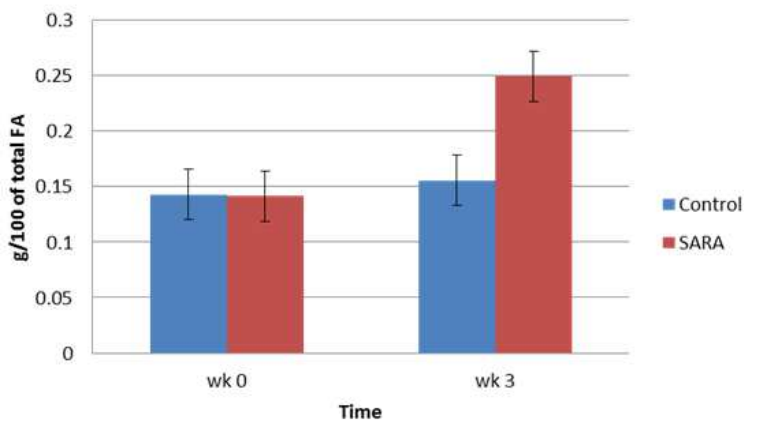

Fig. 2. The treatment increased $(\mathrm{p}<0.05)$ milk fat concentration of odd-chain FA C11:0 and C13:0 as seen in figure a-b 

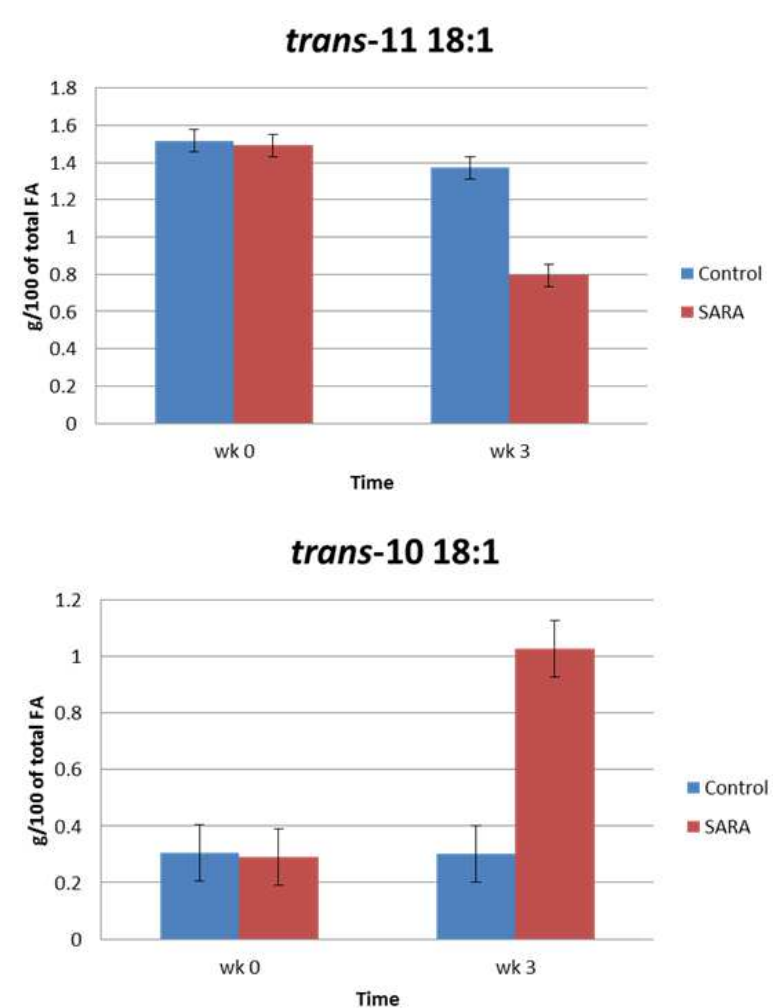

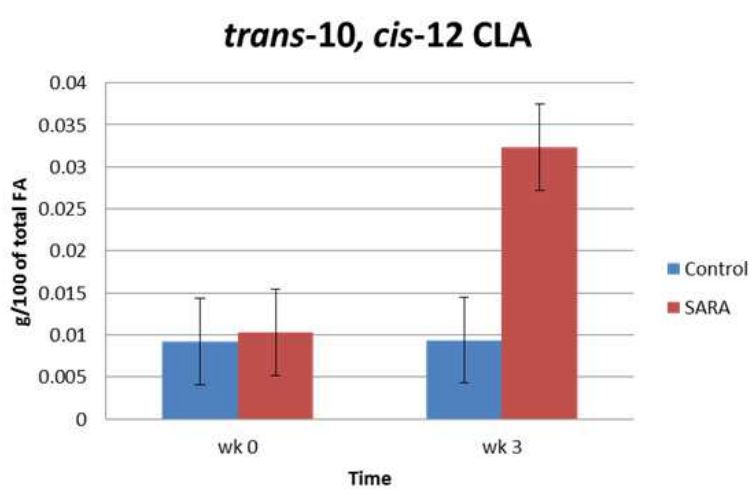

cis-9, trans-11 CLA

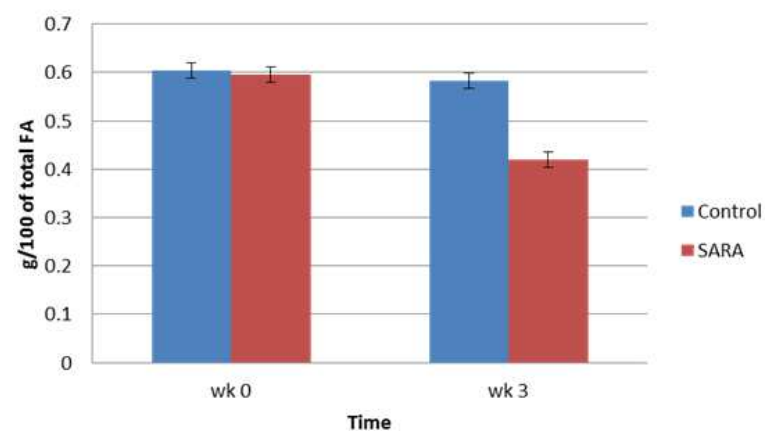

Fig. 3. The LF diet decreased trans-11 18:1 (a) and cis-1, trans-11 CLA (b); and increased trans-10 18:1 (c) and trans-10, cis-12 CLA (d)

The treatment increased $(\mathrm{p}<0.05)$ milk fat concentration $(\mathrm{g} / 100 \mathrm{~g})$ of odd chain FA (including 11:0 and 13:0; Fig. 2), 12:0, 13:0 antiso, cis-9 14:1, cis-12 $18: 1$, cis-13 18:1, trans 6-8 18:1, trans-12 18:1, cis-9, cis-12 18:2 and 20:4 n-6 (Fig. 2). In this study, they were correlated with a decline in milk fat from $3.89 \%$ or 0.76 $\mathrm{kg} / \mathrm{d}$ to 3.25 or 0.73 (Steele et al., 2012). The milk FA profile, likely reflects the decrease concentrate: Forage ratio. During SARA, amylolytic bacteria, which are typically at low levels in the rumen, begin to thrive as the $\mathrm{pH}$ begins to drop (Fievez et al., 2012). Amylolytic bacteria contain low levels of branched chain FA, however they are also enriched with linear-odd chain FA and anteiso branched chain FA (Fievez et al., 2012). Odd-chain FAs are formed through elongation of propionate, which is produced by the increased amylolytic bacteria (Fievez et al., 2012). Colman et al. (2010) demonstrated that odd-chain FAs, such as C15:0 and $\mathrm{C} 17: 0$, increased with a more concentrated diet, mirroring our results. AlZahal et al. (2009), found that cows receiving lower forage diets also had greater milk concentrations of odd chain FA like C11:0 and C13:0. Furthermore, another study by Craninx et al. (2008), demonstrated that cows with acidosis have more oddchain FA in their milk compared to branched-chain FA, mimicking patterns similar to our experiment.
The treatment reduced trans-11 18:1 and cis-9, trans11 CLA; and increased trans-10 18:1; trans-10, cis-12 CLA and trans-9, cis-11 CLA (Fig. 3). In this study the trans-10 isomers were associated with a decline in milk fat (\%) from 3.89 to 3.25 (Steele et al., 2012). During acidosis, these FA are a result of intermediates from a secondary biohydrogenation pathway of C18:2 n-6 (Fuentes et al., 2009). An increase in ruminally derived trans-10 isomer is closely linked with milk fat depression, (Bauman and Griinari, 2003). Trans-10 C18:1 reacts to dietary factors and its concentrations have been negatively associated with milk fat yield in cows (Bernard et al., 2008). This could explain why our SARA induced cows experienced a decrease in milk fat production.

A study by Griinari et al. (1998) observed an increase in trans octadecenoic acids and trans-10 isomers of transoctadecenoic acid, resulting in milk fat depression. Therefore, they supported the theory that low rumen $\mathrm{pH}$, resulting from feeding low fiber diets, results in the incomplete biohydrogenation of FA (Griinari et al., 1998). AlZahal et al. (2010) also demonstrated that cows being fed moderate forage: Concentrate had a greater increase in trans-10 FA and trans-9, cis-11 conjugated linoleic acid than high forage: Concentrate. Additionally, the levels of the isomers were also related to the polyunsaturated FA levels (AlZahal et al., 2010). Baumgard et al. (2000) 
detected a relationship in milk fat depression and increases in trans-10 cis-12 and C18:1 trans-10. In addition Fuentes et al. (2009), also demonstrated that a $\mathrm{pH}$ of 5.6 decreased the trans-11 C18:1 and cis-9, trans-11 CLA; and increased the concentration of trans-10 C18:1, trans-10 cis $15 \mathrm{C} 18: 2$ and trans-10, cis-12 CLA. These studies indicate that the biohydrogenation intermediated FA in milk could be indicators the presence of SARA, as they are closely linked to rumen $\mathrm{pH}$.

\section{Conclusion}

In conclusion, our study demonstrated that SARA was associated with shifts in OBCFAs concentration in milk, due likely to shifts in the rumen microbiome. These shifts could be used to detect SARA, by pooling milk samples and avoiding invasive tests. Currently, the use of milk FA profile in detecting SARA is limited to experimental treatment, but there is potential for clinical application.

\section{Acknowledgment}

We acknowledge the continued support received from Dairy Farmers of Ontario and the Natural Sciences and Engineering Research Council of Canada (B. W. McBride). We also appreciate the technical help provided by Matthew Walpole, Dave Renaud, Jing Zhang (University of Guelph Genomics Facility), Laura Wright and the staff at the Ponson by Dairy Research Station.

\section{Author's Contributions}

Courtney Mitchell: Contributed to data interpretation and writing of the manuscript.

Ousama AlZahal: Conducted experiment, analyzed data, and contributed to writing of manuscript.

Mamun Or-Rashid: Conducted FA analysis and contributed to data interpretation.

Michael Alexander Steele: Conducted experiment and reviewed manuscript.

Brian William McBride: The principal investigator of the study.

\section{Ethics}

This study was approved by the Animal Care Committee at the University of Guelph, under the guidelines of the Canadian Council for Animal Care.

\section{References}

AlZahal, O., E. Kebreab, J. France and B.W. McBride, 2007. A mathematical approach to predicting biological values from ruminal $\mathrm{pH}$ measurements. J. Dairy. Sci., 90: 3777-3785.

DOI: $10.3168 /$ jds.2006-534
AlZahal, O., M.M. Or-Rashid, S.L. Greenwood, M.S. Douglas and B.W. McBride, 2009. The effect of dietary fiber level on milk fat concentration and fatty acid profile of cows fed diets containing low levels of polyunsaturated fatty acids. J. Dairy Sci., 92: 1108-1116.

DOI: $10.3168 /$ jds.2008-1472

AlZahal, O., M.M. Or-Rashid, S.L. Greenwood and B.W. McBride, 2010. Effect of subacute ruminal acidosis on milk fat concentration, yield and fatty acid profile of dairy cows receiving soybean oil. J. Dairy Res., 77: 376-384. DOI: $10.1017 / \mathrm{S} 0022029910000294$

Bauman, D.E. and J.M. Griinari, 2003. Nutritional regulation of milk fat synthesis. Ann. Rev. Nutr., 23: 203-227.

DOI: 10.1146/annurev.nutr.23.011702.073408

Baumgard, L.H., B.A. Corl, D.A. Dwyer, A. Sæbø and D.E. Bauman, 2000. Identification of the conjugated linoleic acid isomer that inhibit milk fat synthesis. Am. J. Physiol., 278: R179-R184.

Bernard, L., C. Leroux and Y. Chilliard, 2008. Expression and nutritional regulation of lipogenic genes in the ruminant lactating mammary gland. Adv. Exp. Med. Biol., 606: 67-108.

DOI: 10.1007/978-0-387-74087-4_2

Chilliard, Y., F. Glasser, A. Ferlay, L. Bernard and J. Rouel et al., 2007. Diet, rumen biohydrogenation and nutritional quality of cow and goat milk fat. Eur. J. Lipid Sci. Technol., 109: 828-855.

DOI: 10.1002/ejlt.200700080

Colman, E., W.B. Fokkink, M. Craninx, J.R. Newbold and B. De Bates et al., 2010. Effect of induction of Sub-Acute Ruminal Acidosis (SARA) on milk fat profile and rumen parameters. J. Dairy Sci., 93: 4759-4773. DOI: 10.3168/jds.2010-3158

Craninx, M., A. Steen, H. Van Laar, T. Van Nespen and J. Martn-Tereso et al., 2008. Effect of lactation stage on the odd- and branched-chain milk fatty acids of dairy cattle under grazing and indoor conditions. J. Dairy Sci., 91: 2662-2677. DOI: $10.3168 /$ jds.2007-0656

Donovan, J., 1997. Subacute acidosis is costing us millions. Hoard's Dairymen, 142: 666-666.

Enemark, J., 2009. The monitoring, prevention and treatment of Sub-Acute Ruminal Acidosis (SARA): A review. Vet. J., 176: 32-43. DOI: $10.1016 / j . t v j 1.2007 .12 .021$

Fievez, V., E. Colman, J.M. Castro-Montoya, I. Stefanov and B. Vlaeminck, 2012. Milk odd- and branchedchain fatty acids as biomarkers of rumen function-an update. Anim. Feed Sci. Tech., 172: 51-65. DOI: 10.1016/j.anifeedsci.2011.12.008 
Fuentes, M.C., S. Calsamiglia, P.W. Cardozo and B. Vlaeminck, 2009. Effect of $\mathrm{pH}$ and level of concentrate in the diet on the production of biohydrogenation intermediates in a dual-flow continuous culture. J. Dairy Sci., 92: 4456-4466. DOI: $10.3168 /$ jds.2008-1722

Garrett, E.F., K.V. Nordlund, W.J. Goodge and G.R. Oetzel, 1997. A cross-sectional field study investigating the effect of periparturient dietary management on ruminal $\mathrm{pH}$ in early lactation dairy cows. J. Dairy Sci., 80: 169-169.

Griinari, J.M., D.A. Dwyer, M.A. McGuire, D.E. Bauman and D.L. Palmquist et al., 1998. Trans-Octadecenoic acids and milk fat depression in lactating dairy cows. J. Dairy Sci., 81: 1251-1261. DOI: $10.3168 /$ jds.S0022-0302(98)75686-3

Or-Rashid, M., N.E. Odongo, T.C. Wright and B.W. McBride, 2009. Fattyacid profile of bovine milk naturally enhanced with docosahexaenoic acid. J. Agric. Food Chem., 57: 1366-1371. DOI: $10.1021 /$ jf802989p

Patel, M., E. Wredle and J. Bertilsson, 2013. Effect of dietary proportion of grass silage on milk fat with emphasis on odd- and branched-chain fatty acids in dairy cows. J. Dairy Sci., 96: 390-397. DOI: $10.3168 /$ jds.2012-5441

Shingfield, K.J., C.K. Reynolds, B. Lupoli, V. Toivonen and M.P. Yurawecz et al. 2005. Effect of forage type and proportion of concentratein the diet on milk fatty acid composition in cows given sunfloweroil and fish oil. Anim. Sci., 80: 225-238.

DOI: $10.1079 /$ ASC41820225
Plaizier, J.C., D.O. Krause, G.N. Gozho and B.W. McBride, 2009. Subacute ruminal acidosis in dairy cows: The physiological causes, incidence and consequences. Vet. J., 176: 21-31. DOI: $10.1016 /$ j.tvj1.2007.12.016

Steele, M.A., L. Dionissopoulos, O. AlZahal, J. Doleman and B.W. Mcbride, 2012. Rumen epithelial adaptation to ruminal acidosis in lactating cattle involves the coordinated expression of insulin-like growth factor-binding proteins and a choleseroigenic enzyme. J. Dairy Sci., 95: 318-327. DOI: $10.3168 /$ jds.2011-4465

Stone, W.C., 1999. The effect of subclinical rumen acidosis on milk components. Proceedings of the Cornell Nutrition Conference of Feed Manufacturers, Syracuse, (FMS' 99), N.Y. Cornell University, Ithaca, NY, USA, pp: 40-46.

Van Nespen, T., B. Vlaeminck, W. Wanzele, W. Van Straalen and V. Fievez, 2005. Use of specific milk fatty acids as diagnostic tool for rumen acidosis in dairy cows. Commun. Agric. Applied Biol., 70: 1-4.

Vlaeminck, B., V. Fievez, A.R.J. Cabrita, A.J.M. Fonseca and R.J. Dewhurst, 2006. Factors affecting odd- and branched-chain fatty acids in milk: A review. Anim. Feed Sci. Technol., 131: 389-417. DOI: 10.1016/j.anifeedsci.2006.06.017 